Research Journal of Applied Sciences 5 (1): 27-31, 2010

ISSN: $1815-932 \mathrm{X}$

(C) Medwell Journals, 2010

\title{
Gender as a Determinant of Individual Lifestyle for Sustainable Development in Africa
}

\author{
${ }^{1}$ Shehu Raheem Adaramaja, ${ }^{2}$ Onasanya Samuel Adenubi and ${ }^{3}$ Ursula Nnbueze \\ ${ }^{1}$ Department of Human Kinetics and Health Education, Faculty of Education, \\ University of Ilorin, P.M.B. 1515, Ilorin, Nigeria \\ ${ }^{2}$ Department of Science Education, University of Ilorin, P.M.B. 1515, Ilorin, Nigeria \\ ${ }^{3}$ Department of Physical and Health Education, \\ Enugu State University of Technology, Enugu State, Nigeria
}

\begin{abstract}
The study examined the relationship between gender and individual choice of lifestyle factors. The lifestyle factors of smoking, alcohol consumption, sedentary lifestyle, nutritional habit and sexual behaviour constitute the dependent variables, while gender (male and female) constitute the independent variables. Ex-post facto research design of $2 \times 5$ non-experimental factorial sub-design was used. The design afforded the researchers opportunity to juxtapose the two independent variables in order to study their relationship on the dependent variables. Cluster random sampling technique was used to select samples for the study. A total of 1350 randomly selected samples were used for the study. A questionnaire, which consists of 45 items on the practice of lifestyle factors, developed by the researchers and pilot tested was used for the study, using Goffman split-half model, a reliability analysis scale of $0.918 \mathrm{r}$ was obtained. Data collected were statistically analysed using descriptive and inferential statistics of student t-test. The results indicated that gender does not influence or determine respondents smoking habit, alcoholic lifestyle, nutritional habit and unsafe sexual practices of the people of Kaduna State. It was also found that significant differences exist in male and female drug habit and physical inactivities (sedentary lifestyle) in Kaduna State. The researchers recommended that public health education should be intensified to improve people's awareness of the consequences of unhealthy lifestyle, with the aim of encouraging them to make right decisions or choices among others.
\end{abstract}

Key words: Lifestyle factors, local burukutu, gender, African alcoholics, Kaduna State

\section{INTRODUCTION}

Lifestyle are patterns of behavioural choices made from the alternative that are available to people according to their socio-economic circumstances and to the ease with which they are able to choose certain ones over others. Lifestyles are the behaviour of choice, which affect ones fitness and health status (Blair, 1995). Smoking, diet (food type and habit) and alcohol consumption are particularly important in this context. Each of these variables had at least a weak influence upon both fitness and health status in their own right and can potentially confound assessments based upon either occupation or patterns of leisure activity.

The individual lifestyles constitute what he does and what he fails to do, ranging from smoking, overeating, inactivity, alcoholism, drug abuse and participation in unprotected sexual relationship. The World Health Organization (1993) and Bruce et al. (2000) reported that there is a strong negative relationship between peoples mortality rate and lifestyle practices. This has serious negative consequences on the national health status and survival.

Lifestyle factors, such as physical activity, dietary habits, smoking and alcohol intake are related to relative weight gain in both men and women (Seidell and Flegal, 1997; Trembley, 1999; Lissner and Heitman, 1995; Molarius et al., 1997). Molarius (2003) reported a prevalence of obesity by gender and age group among his study population in Germany (i.e., $12 \%$ of men and $14 \%$ of women were obese). Also, about one-fifth of the study populations were reported to be physically inactive and physical inactivity was most common among young men (20-33 years) than women. In Nigeria, it is observed especially in the cities that heavy use of alcohol and drug abuse are very common among men especially young men than women. Dietary attitudes shows a similar patterns as heavy alcohol use and drug abuse. Men are observed to be generally active than women especially in rural areas of Nigeria. Further differences in health status and lifestyle

Corresponding Author: Shehu Raheem Adaramaja, Department of Human Kinetics and Health Education, Faculty of Education, University of Ilorin, P.M.B. 1515, Ilorin, Nigeria 
between men and women have been attributed to gender specific health and longetivity related behaviours. For example, women are more likely than men to describe themselves as non-drinkers and non-smokers, yet are less physically active (Ross and Bird, 1994). Women also tend to be more concerned about health matters and to use health care system for treatment compare to men (Verbrugge, 1984; McDonough and Walters, 2001). Gender disparities in health are often linked to differences between men and women in exposure to lifestyle factors. Gender is one among many other demographic factors of age, religion, socio-economic status, marital status and environmental factor that influence individual choice of lifestyle factors. The individual lifestyle or behaviour can influence his state of health and individual's state of health can influence lifestyle choice. Branch (1985), Breslow and Breslow (1993), Blair (1995), Rogers (1995) and Manton et al. (1991) were of the opinion that individuals with healthy lifestyle tend to live longer than others and that individuals with unhealthy lifestyle tend to die sooner than others. Healthy lifestyle factors of concern consists of regular exercise, good diet, non-smoking, non-alcohol consumption, safe drug use and avoidance of casual and unprotected sex. Healthy lifestyle helps to prevent weight gain, high blood pressure, stress, early mortality and the spread of HIV/AIDS. On the other hand, unhealthy lifestyle of individuals are those negative health behaviours that had been scientifically proven to be harmful to one's health.

They individually or collectively have direct or indirect consequences on the health and well being of individuals. These include poor dietary habits or excessive eating, lack of exercise or sedentary activities, smoking, casual sex and heavy use of alcohol. The implications of unhealthy lifestyle are enormous these includes problems of malnutrition, obesity, liver cirrhosis, cardiac diseases, HIV/AIDS, accidents, untimely deaths and many others.

Life chances and choices are very clearly gendered in all parts of the world, no country treats its women as well as it treats its men. Gender is not just a question of socially acquired female and male roles, it is an organizing principle of social life. In defining gender as a key determinant of health we recognize not only how central the power relationship between men and women is to our daily life and wellbeing but that it can be a question of life and death. It is therefore, important to examine how gender influences the choice of a particular lifestyle heavy use of alcohol for example.

Alcoholism as a lifestyle is characterized by excessive use of alcohol to the point of over-dependence or addiction (Asuni et al., 1994). Alcoholism could be differentiated from excessive and heavy social drinking.
Excessive drinking goes beyond what is traditional and customary in one's country. Alcoholics are these excessive drinkers whose health or family relationships or work performance are adversely affected by drinking. In traditional African Communities drinking (alcohol consumption as a lifestyle) occurs not only at home and after work but also outside the home and at the time of weddings and other special ceremonies. African alcoholics fall into two main groups. The first are those men and women, who have not left the traditional setting. Their drinking was originally in conformity with the custom in their village or community but unlike most of their friends drinking became more and more excessive and thereby set them apart from most of their neighbours. Even though, such men and women with alcoholic problem might not drink the entire year simply because of the unavailability of alcoholic drinks. However, when the alcohol drink is available they may be the ones, who would drink without control and perhaps be drunk much of each day. The other type of alcoholic is found among men and women who have moved away from the traditional way of life and lived in cities. Such alcoholics may present symptoms of one of the personality disorders or social uneasiness and inability to tolerate tension or less frequently, symptoms of a more psychiatric illness.

On smoking, Rowland et al. (2002) observed that the rate of smoking among women now outnumbered the men, thus, cigarette smoking was associated with short and irregular cycles (menstrual cycles). The odds of having irregular cycles were $3.6 \%$ among women, who smoked more than a pack of cigarette a day compared with non-smokers. This assertion was corroborated by Molarius (2003), when he reported that women were often smokers than men, except among the elderly. Smoking is seriously implicated in heart diseases and account for many deaths from lung cancer to other cancers among women than men (Rowland et al., 2002).

The same parameters applies to the choice of individual choice of other lifestyle factors. This study therefore, examined the influence of gender on the choice of lifestyle factors like heavy use of alcohol, nutritional status, smoking, drug habit, lifestyle and unsafe or indiscriminate sexual practices.

Research hypothess: The following hypotheses were formulated for the study:

- Gender of the respondents in Kaduna State does not significantly determine the smoking habit of the people for sustainable development in Africa

- Gender of the respondents in Kaduna State does not significantly determine the alcoholic lifestyle of the people for sustainable development in Africa 
- Gender of the respondents in Kaduna State does not significantly determine the sedentary lifestyle of the people for sustainable development in Africa

- Gender of the respondents in Kaduna State does not significantly determine the nutritional habit of the people for sustainable development in Africa

- Gender of the respondents in Kaduna State does not significantly determine the drug habit of the people for sustainable development in Africa

- Gender of the respondents in Kaduna State does not significantly determine the sexual behaviour of the people for sustainable development in Africa

\section{MATERIALS AND METHODS}

Ex-post facto research design of $2 \times 5$ non-experimental factorial sub-design was used. Thus, the lifestyle factors of smoking, alcohol consumption, sedentary lifestyle, nutritional habit, drug habit and sexual behaviour constitute the dependent variables, while gender (male and female) constitute the independent variables. The population for this study consist of all individuals aged 16 years and above living in both rural and urban areas of Kaduna State, Nigeria as at the time of this study. A total of 1350 samples were randomly selected from six rural and six urban areas selected from the three constitutional recognized senatorial districts of Kaduna State, Nigeria using cluster random sampling technique. A self structured and developed questionnaire tagged Questionnaire on Relationship Between Gender and Lifestyles of the people of Kaduna State, Nigeria (QRGLKSN). Face and content validity of the research instrument was established by distributing copies of the questionnaire to jurors in the field of health education. The instrument was pilot tested, using Goffman split-half reliability model through the Statistical Package for Social Science (SPSS) a reliability analysis scale of $0.9181 \mathrm{r}$ was obtained. The instrument was administered with the help of research assistants and interpreters, who are fluent in various local languages of Hausa, Fulani, Kargo, Daba etc. that exists in the state. Inferential statistics of student t-test was used to analyzed the six hypotheses generated for the study at $0.05 \alpha$-level of significance.

\section{RESULTS AND DISCUSSION}

Table 1 shows that the calculated t-value for smoking habit (0.60), alcoholic lifestyle (1.67), nutritional habit $(-0.54)$ and sexual behaviour $(-0.84)$ of the respondents were less than critical value of 1.96 with a degree of freedom 1348 at $0.05 \alpha$-level of significance. Therefore, the null hypotheses that says there are no significant differences in the adopted lifestyles of smoking, alcoholic lifestyle, nutritional habit and sexual behaviour were upheld. This connotes that significant difference does not exist in the adopted lifestyles (smoking, alcoholic lifestyle, nutritional habit and sexual behaviour) and gender of the respondents in Kaduna State. This implies that gender of the respondents does not influence the respondents smoking habit, alcoholic lifestyle, nutritional habit and sexual behaviour of the people of Kaduna State.

Table 1 also reveals that the calculated t-value for sedentary lifestyle (3.43) and drug habit $(-2.65)$ were greater than the critical value of 1.96 with a degree of freedom 1348 at $0.05 \alpha$-level of significance. Therefore, the null hypotheses that says there are no significant differences in the adopted lifestyles of sedentary lifestyle and drug habit of the respondents and their gender were rejected. This implies that significant differences exist between the adopted lifestyles (sedentary and drug habit) and the gender of the respondents in Kaduna State.

The findings that significant relationship does not exist between gender and the practice of lifestyle factors like smoking, alcoholic lifestyle, nutritional habit and sexual behaviour of the respondents in Kaduna State as presented in Table 1 is not in conformity with the submission of Verbrugge (1984) and McDonough and Walters (2001) that gender disparities in health are often linked to differences between men and women in exposure to lifestyle factors. Also, the finding was not in accord with Molarius (2003), who reported a prevalence of obesity by gender and negatively skewed to women among his study population (12\% of men and $14 \%$ of women were obese) that the rate of smoking among women are now outnumbered men. On gender and alcohol consumption, a visit to southern parts of Kaduna State would clearly testify to the fact that both gender were actively involve in alcohol consumption. However, a slight increase is found among men than women as shown in their arithmetic means in Table 1. Also, majority of the respondents (cut across gender) in the study area, agreed that they feed on local foods everyday of the week (papa and akara, tuwo masara, gari, yams, rice, beans and other cereal products). The insignificant difference observed in gender and their sexual behaviour is due to the fact that both gender were actively involve in indiscriminate sexual behaviour.

On smoking, a contradictory report was also found in Rowland et al. (2002), when they observed that the rate of smoking especially from kitchens among women are now outnumbered men thus, cigarette smoking was associated with short and irregular menstrual cycles in women. The reason for this contradictories is not known, it is however, open for further research to find out why 
Res. J. Applied Sci., 5 (1): 27-31, 2010

\begin{tabular}{|c|c|c|c|c|c|c|c|c|}
\hline Lifestyle factors & Gender & No. of cases & Mean \pm S.D & $\mathrm{SE}$ & $\mathrm{DF}$ & Cal. t-value & Critical value & Remarks \\
\hline \multirow[t]{3}{*}{ Smoking } & Male & 1038 & $4.9094 \pm 3.817$ & 0.118 & - & - & - & - \\
\hline & Female & 312 & $4.7596 \pm 4.042$ & 0.229 & 1348 & 0.60 & 1.96 & Not sig \\
\hline & Total & 1350 & & & & & & \\
\hline \multirow{3}{*}{ Alcoholic lifestyle } & Male & 1038 & $7.9017 \pm 6.044$ & 0.188 & - & - & - & - \\
\hline & Female & 312 & $7.2596 \pm 5.593$ & 0.317 & 1348 & 1.67 & 1.96 & Not sig \\
\hline & Total & 1350 & & & & & & \\
\hline \multirow[t]{3}{*}{ Sedentary lifestyle } & Male & 1038 & $8.0032 \pm 2.707$ & 0.084 & - & - & - & - \\
\hline & Female & 312 & $8.6002 \pm 2.691$ & 0.153 & 1348 & 3.43 & 1.96 & Sig. \\
\hline & Total & 1350 & & & & & & \\
\hline \multirow[t]{3}{*}{ Nutritional habit } & Male & 1038 & $15.9094 \pm 4.304$ & 0.134 & - & - & - & - \\
\hline & Female & 312 & $16.0609 \pm 4.607$ & 0.261 & 1348 & -0.54 & 1.96 & Not sig \\
\hline & Total & 1350 & & & & & & \\
\hline \multirow[t]{3}{*}{ Drug habit } & Male & 1038 & $7.1657 \pm 5.650$ & 0.175 & - & - & - & - \\
\hline & Female & 312 & $8.1250 \pm 5.449$ & 0.308 & 1348 & -2.65 & 1.96 & Sig. \\
\hline & Total & 1350 & & & & & & \\
\hline \multirow[t]{3}{*}{ Sexual behaviour } & Male & 1038 & $9.4971 \pm 4.134$ & 0.128 & - & - & - & - \\
\hline & Female & 312 & $9.7276 \pm 4.521$ & 0.266 & 1348 & -0.84 & 1.96 & Not sig \\
\hline & Total & 1350 & & & & & & \\
\hline
\end{tabular}

significant relationship does not exist between gender and some lifestyle factors like smoking, alcoholic lifestyle, nutritional habit and sexual behaviour. The finding that gender is significantly related to sedentary lifestyle and drug habit of the respondents, is corroborated by the submission of Molarius (2003), who reported a prevalence of obesity due to physical inactivity by gender and age group among his study population (i.e., $12 \%$ of men and $14 \%$ of women were obese). About one-fifty of the study populations were reported to be physically inactive and physical inactivity was most common among young men (25-44 years) than women. Seidell and Flegal (1997), Lissner and Heitman (1995), Molarius (2003) and Tremblay (1999) observed that physical inactivity, smoking, drug abuse and alcohol intake are related to relative weight gain in both men and women. The finding that gender is related to drug habit among the people of Kaduna State is in agreement with the submission of Folawiyo (1990), who observed especially in Nigeria cities that heavy use of alcohol and drug abuse are very common among men especially young men than women.

\section{CONCLUSION}

Alcoholic lifestyle, nutritional habit, smoking and unsafe sexual behaviour are found not to be significantly related to gender (male and female). A visit to places like Kafancha, Kwoi, Zonkwa, Kagoro, Fadan Kagoma and Gantu in the southern parts of Kaduna Sate and Samaru Zaria, Kwangila, Mando, Kawo and Buruku in the northern parts of the state would clearly testify that both gender are actively involve in the production and consumption of alcohol (local Burukutu), feed on majorly cereals crops and no clearly distinction as to a particular gender with high rate of smoking. However, it is a fact that anybody that is drunk is bound to sexually misbehave. Conclusively, young men than women in Kaduna State engages more in sedentary activities like long hours of sitting down at popular local joints to enjoy burukutu locally made alcohol, petty trading and others. This appears not to favour the men health wise as women were barred to farming for a more strenuous activities, when young men engages in pleasurable activities. The effect of this is a number of health related diseases that like obesity, cancer, cardiac diseases, high blood pressure and untimely deaths that are common in the state.

Also many of those young men were easy weapons for political jobbers and religious fanatics in the state, who readily recruit them for political and religious disturbances that are abound in Kaduna State, Nigeria in recent times.

\section{RECOMMENDATIONS}

- Since the lifestyle exhibited by an individual does not spring up in a day, health education of children and youths (especially adolescents) should be intensified in the primary and secondary schools in order to make them appreciate the adverse effects of alcohol, drug abuse, smoking, inactivity and indiscriminate sexual behaviour

- Religions and community leaders as well as opinion leaders should be involved in the crusade against unhealthy lifestyles

- Public health education should be intensified to improve people's awareness of the consequences of unhealthy lifestyles with the aim of encouraging them to make right decision and choices 
- The young adolescents men, who are mostly found in the habit of excessive drinking, drug abuse, smoking and indiscriminate sexual practices should be positively counseled to modify their behaviours and encourage to adopt healthy lifestyles

\section{REFERENCES}

Asuni, T., F. Schöenberg and C.R. Swift, 1994. Mental Health and Diseases in Africa. 2nd Edn., Churchill Livingstone, New York, pp: 92-93.

Blair, S.N., 1995. Exercise prescription for health. Quest, 47: 338-353.

Branch, L.G., 1985. Health practices and incident disability among the elderly. Am. J. Public Health, 75: 1436-1439.

Breslow, L. and N. Breslow, 1993. Health practices and disability: Some evidence from Alameda county. Prev. Med., 22: 86-95.

Bruce, N., R. Perez-Padilla and R. Albalak, 2000. Indoor air pollution in developing countries: A major environmental and public health challenge. Bull. World Health Org., 78: 1078-1092.

Folawiyo, A.F.A., 1990. Promoting effective health for all by the year 2000: Myths and realities. J. Nig. Assoc. Phys. Health Recreation, 7: 71-78.

Lissner, L. and B.L. Heitman, 1995. Dietary fat and obesity: Evidence from epidemiology. Eur. J. Clin. Nutr., 49: 79-90.

Manton, K.G., E. Stallard and H.D. Tolley, 1991 . Limit to human life expectancy: Evidence, prospects and implications. Popul. Dev. Rev., 17: 603-637.
McDonough, P. and V. Walters, 2001. Gender and health: Reassessing patterns and explanations. Social Sci. Med., 52: 547-559.

Molarius, A., 2003. The contribution of lifestyle factors to socioeconomic differences in obesity in men and women: A population based study in Sweden. Eur. J. Epidemiol., 18: 227-234.

Molarius, A., J.C. Seidell, K. Kuulasma and A.J. Dobson, 1997. Smoking and relative body weight: An international perspective from the WHO MONICA project. J. Epidemiol. Commun. Health, 51: 252-260.

Rogers, R.G., 1995. Socio-demographic characteristics of long live and healthy individuals. Popul. Dev. Rev., 21: 33-58.

Ross, E.C. and E.C. Bird, 1994. Sex stratification and health lifestyle: Consequences for men's and women's perceived health. J. Health Social Behav., 35: 161-178.

Rowland, A.S., D.D. Baird, S. Long, G. Wegienka, S.D. Harlow, M. Alavanja and D.P. Sandler, 2002. Influence of medical conditions and lifestyles factors on the menstrual cycle. Epidemiology, 13: 668-674.

Seidell, J.C. and K.M. Flegal, 1997. Assessing obesity: Classification and epidemiology. Br. Med. Bull., 53: $238-252$.

Tremblay, A., 1999. Physical activity and obesity. Best Pract. Res. Clin. Endocrinol. Metab., 13: 121-129.

Verbrugge, L.M., 1984. A health profile of older women with comparisons of older men. Res. Aging, 6: 291-322.

World Health Organization, 1993. Environmental health profile. Technical Report Series, pp: 186. 